\title{
MONITORING DAN EVALUASI DAERAH ALIRAN SUNGAI DENGAN PENGINDERAAN JAUH DAN SISTEM INFORMASI GEOGRAFIS
}

\author{
Beny Harjadi \\ Peneliti Madya Bidang Pedologi dan Penginderaan Jauh \\ Pada Balai Penelitian Kehutanan (BPK) Solo \\ Badan Penelitian dan Pengembangan Kehutanan, Departemen Kehutanan \\ E-mail:adbsolo@yahoo.com
}

\begin{abstract}
The characteristics of the landcover of a territory were really influenced by the condition biophysical and social his community's economics. To the territory with the high rainfall had a rare population, the pattern of the landcover was more dominant to the annual crop, conversely to the high rainfall territory had a solid population the pattern of the land cover was more dominant in crops. Whereas to the dry territory (low rain) with the rare inhabitants, the pattern of the bis land cover was dominated the meadow and the crop kept dry. The requirement would the latest data, the high accuracy, to the area that was wide to monitor the change in one unity of the management of watershed. This research aimed at studying the application of remote sensing (RS) and the geographical information system (GIS) to monitoring and the evaluation of watershed. Physical conditions for the land that was dominated by the land form of the mountainous land and bills with the slope that was steep until precipitous, caused the territory around Grindulu Sub Watershed the potential would the occurrence of the landslide. This landslide incident was also supported by the rock situation that has begun to go mouldy resulting from the disintegration by the hot influence and rain as well as decomposition. Although having some areas of the land that was dominated the bare-rock and the rock-outcrop, but because the land cover was relatively dense in the area of mountains and hills then year round the Grindulu river had not been dry.
\end{abstract}

Keywords: landslide, land use change, monitoring and evaluation, remote sensing (RS)

\section{PENDAHULUAN}

Pengelolaan DAS dengan permasalahan yang komplek, diperlukan penanganan secara holistik, integral dan koordinatif. Sumber daya alam yang berupa hutan (vegetasi), tanah, dan air mempunyai peranan yang penting dalam kelangsungan hidup manusia sehingga dalam pemanfaatannya perlu dilakukan secara optimal dan lestari. Kerusakan sumber daya alam hutan (SDH) yang terjadi saat ini telah menyebabkan terganggunya keseimbangan lingkungan hidup daerah aliran sungai (DAS) seperti tercermin pada sering terjadinya erosi, banjir, kekeringan, pendangkalan sungai dan waduk serta saluran irigasi. Tekanan yang besar terhadap sumber daya alam oleh aktivitas manusia, salah satunya dapat ditunjukkan adanya perubahan penutupan lahan yang begitu cepat, dan tekanan terhadap luas lahan perlu adanya analisis Analisis Kemampuan Penggunaan Lahan (KPL) (Harjadi, 2007). 
Kebutuhan akan data terkini dengan akurasi tinggi, pada areal yang luas sangat diperlukan untuk memantau perubahan satu kesatuan pengelolaan DAS. Data yang diperoleh dari teknologi Penginderaan Jauh (PJ) yang telah di cek di lapangan digunakan sebagai masukan (input) bagi Sistem Informasi Geografis (SIG) untuk selanjutnya diproses dan dianalisa sehingga diperoleh peta penutupan lahan yang akurat. Melalui proses SIG data dari PJ dapat digunakan untuk mendeteksi perubahan penutupan lahan (Land cover change detection) pada suatu DAS. Dalam hal ini bantuan PJ dan SIG sangat diperlukan untuk membantu keterbatasan dana, waktu dan tenaga kerja dengan hasil yang diperoleh memiliki akurasi tinggi, mudah, cepat dan murah, dapat dilakukan pada setiap waktu.

Kondisi penutupan lahan dan variasi jenis tanah dalam pengelolaan DAS akan sangat berpengaruh pada jenis dan tingkat erosi yang terjadi. Daerah yang kritis oleh akibat erosi tersebut dapat dianalisis secara visual maupun digital dengan PJ. (Harjadi, 2005). Sehingga diharapkan PJ dan SIG dapat membantu perhitungan untuk analisis erosi baik secara kualitatif untuk perencanaan jangka panjang maupun secara kuantitatif untuk perencanaan jangka pendek. Adapun tujuan penelitian ini untuk mengkaji aplikasi PJ dan SIG untuk monitoring dan evaluasi DAS.

\section{METODE PENELITIAN}

\section{Monitoring Kondisi Biofisik DAS}

\section{a. Kedalaman Solum Tanah}

Analisis kedalaman tanah dapat didekati dengan kelas kemiringan lahan yang dihitung dari hasil analisis citra satelit SRTM (Shuttle Radar Thematic Mapper) atau dari hasil interpolasi garis kontur.
Semakin miring kelas lereng maka kedalaman tanah akan semakin dangkal karena lahan mengalami degradasi yang menyebabkan berkurangnya ketebalan solum tanah. Rumus slope (kemiringan lereng) dan aspek (orientasi/arah lereng) sebagai berikut (Singh, 1994):

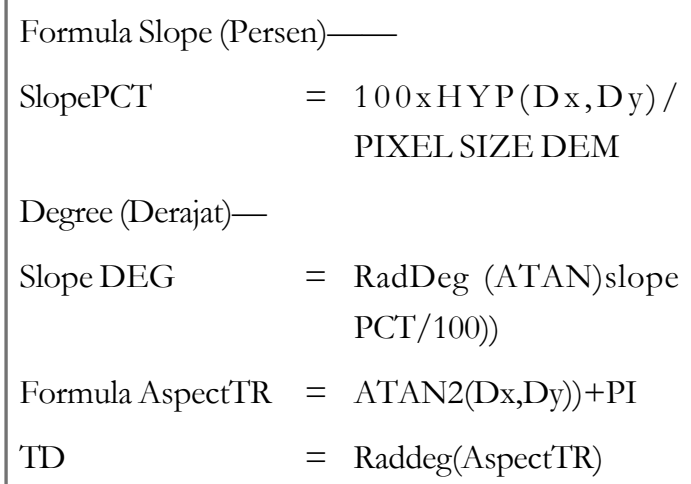

\section{b. Curah Hujan Tahunan}

Analisis curah hujan dengan citra satelit dapat dihitung dengan rumus rasterisasi informasi digital citra satelit dengan membandingkan ketinggian tempat yang berbeda. Semakin tinggi letak daerah di pegunungan maka intensitas hujan akan meningkat pula, dengan rumus perhitungan sebagai berikut (Uboldi dan Chuvieco, 1997):

$$
\begin{aligned}
\mathrm{E} & =\mathrm{R} *(11.9+8.7 * \log (10 . \mathrm{I})) \\
& =\mathrm{R} *(11.9+8.7 * \log (25))
\end{aligned}
$$

dimana :

$\mathrm{E}=$ energi kinetik curah hujan

$\mathrm{R}=$ curah hujan tahunan $(\mathrm{mm})$

$\mathrm{I}=$ intensitas hujan 


\section{c. Evapotranspirasi}

Analisis perhitungan evapotranspirasi (ET) dapat dihitung dengan rumus ET Loss dengan menggunakan faktor penutupan tanaman (Kc), (Proveda, German dan Salazar, 2004) :

$$
\begin{aligned}
\text { ET Loss } & =8 * \mathrm{Kc}^{*} 10=\mathrm{mm} \\
\text { ET Loss1 } & =(\text { ET Loss }+ \text { Area }) / 100 \\
& =\mathrm{m}^{3}
\end{aligned}
$$

\section{Evaluasi DAS Grindulu}

\section{a. SES (Soil Erosion Status)}

Perhitungan erosi kualitatif dengan SES setelah mengklasifikasikan 5 faktor yaitu kemiringan lereng, aspek lereng, kerapatan drainase, penggunaan lahan dan tekstur tanah (Shresta, Honda dan Murai, 1997) (Gambar 1).

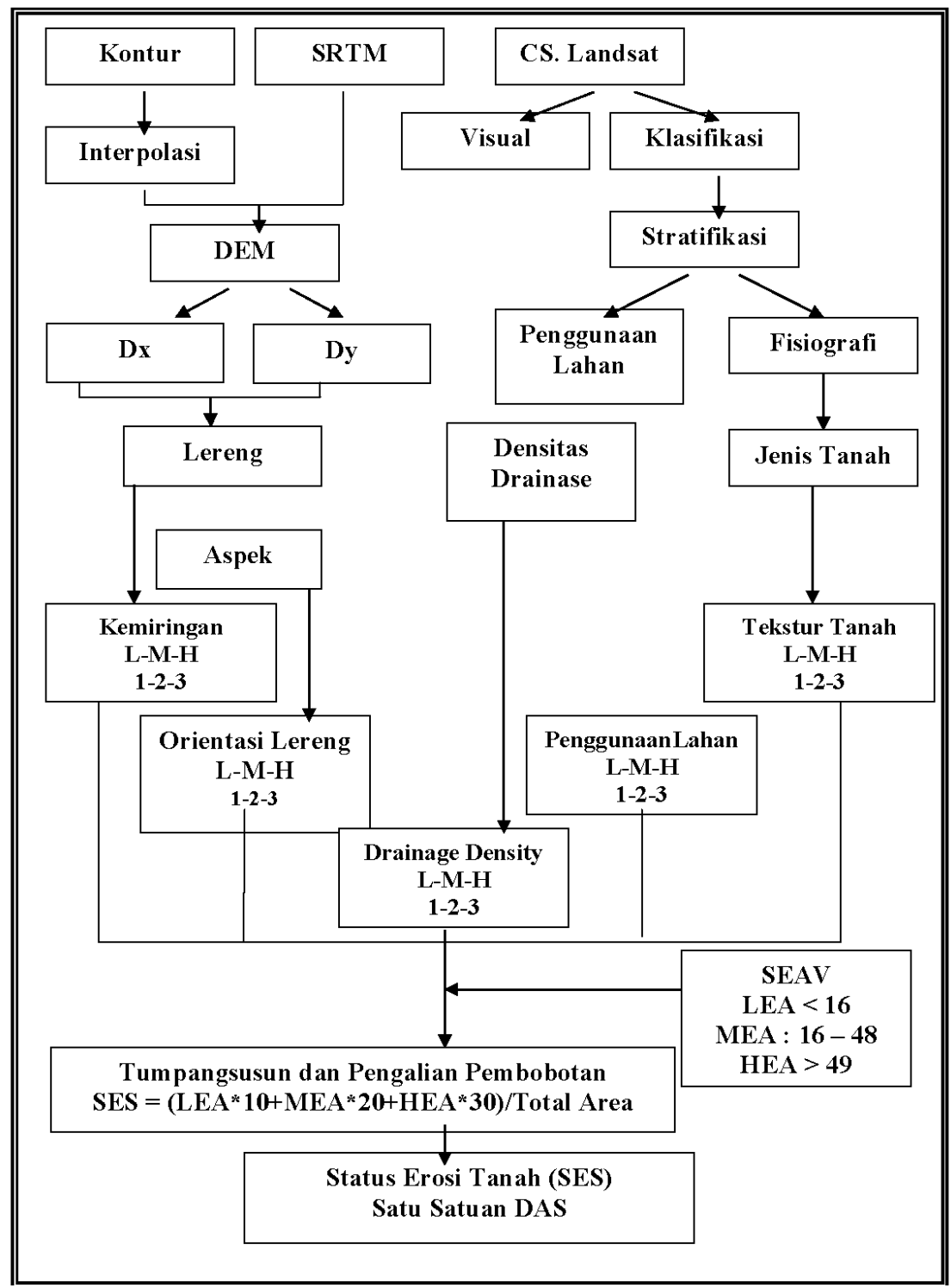

Sumber: Shresta, Honda dan Murai, 1997

Gambar 1. Diagram Alur Analisis Erosi Kualitatif dengan SES 
b. MMF (Morgan Morgan dan Fenney)

Perhitungan erosi secara kualtitatif dengan MMF setelah menganalisis faktor penggunaan lahan (C, A, Et/Eo, dan RD) dan faktor sifat tanah (MS, BD, dan K) serta air permukaan (Morga, Morgan dan Finney, 1984) (Gambar 2).

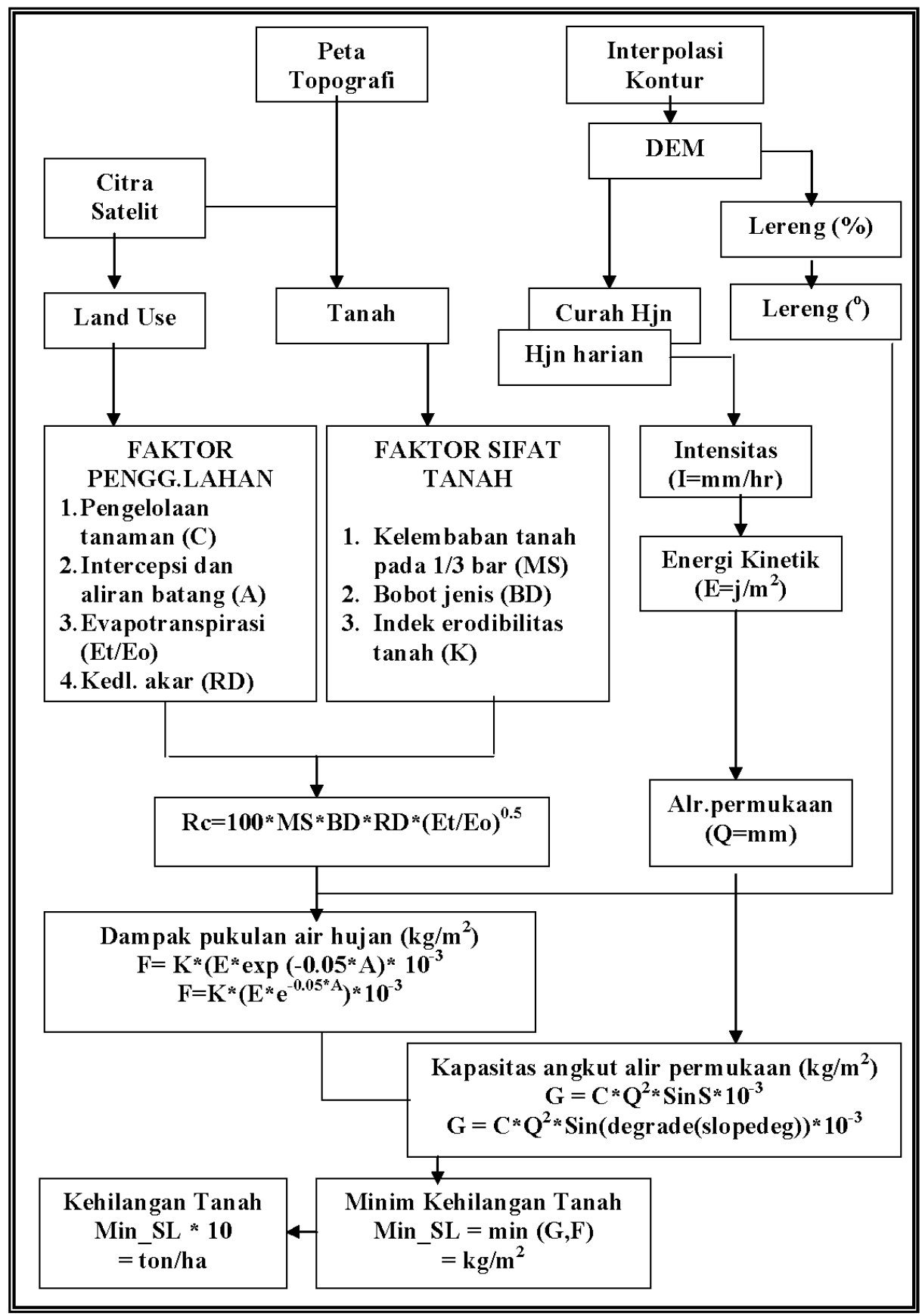

Sumber: Morga, Morgan dan Finney, 1984

Gambar 2. Diagram Proses Analisis Perhitungan Erosi Kuantitatif dengan MMF 
HASIL DAN PEMBAHASAN

\section{A. Monitoring Kondisi Biofisik DAS}

Monitoring merupakan kegiatan rutin dan berkelanjutan dengan tujuan untuk mengetahui sedini mungkin perubahan kerentanan atau kesehatan suatu DAS perlu dilakukan secara reguler. Pemantauan di DAS Grindulu yang masuk di tiga kabupaten dengan daerah dominan di kabupaten Pacitan, yang tercover oleh 12 peta RBI (Rupa Bumi Indonesia) skala 1 : 25.000, meliputi nomer baris dan kolom 1508121 : Kismantoro, 1508-122 : Balong, 1407-644 : Giriwoyo, 1507-433 : Bungur, 1507-434 : Arjosari, 1507 443: Tegal Ombo, 1507-444 : Bungkal, 1407-642 : Kalak, 1507-431 : Pacitan , 1507-432 : Kebon Agung, 1507-441: Losak, 1507-442 : Sukorejo, 1507413: P.Bakung, 1507-414 : Wawaran, dan 1507-441 : Loron.

DAS Grindulu sebelah utara dibatasi oleh Kab. Ponorogo, sebelah timur dibatasi Kab. Trenggalek, sebelah barat dibatasi Kab. Wonogiri dan sebelah selatan dibatasi lautan Indonesia (lihat Tabel 1).

\section{Kedalaman Solum Tanah}

Kedalaman solum tanah dikelaskan berdasarkan kedalaman tanah, semakin tebal tanah maka skornya semakin kecil, sebaliknya semakin tipis tanah maka skor semakin tinggi. Kisaran kelas kedalaman tanah antara lain: kelas 5 (< $15 \mathrm{~cm}), 4(15-30 \mathrm{~cm}), 3$ (30-60 $\mathrm{cm}), 2(60-90 \mathrm{~cm})$, dan 1 (>90 cm).

Gambar 3 menunjukkan skor tingkat bahaya terhadap degradasi lahan pada kategori tingkat rendah dan sedang, karena kedalaman tanah di DAS Grindulu kebanyakan pada kelas sedang (30$60 \mathrm{~cm})$ dan dalam $(>90 \mathrm{~cm})$.

Tabel 2 menyajikan data kedalaman tanah yang masuk kategori sedang yaitu seluas 40.650 ha $(62 \%)$ dan masuk kategori kelas dalam seluas 24.890 ha $(38 \%)$. Walaupun solum tanah cukup dalam namun jika erosi yang terjadi pada tingkat berat seperti erosi jurang dan longsor, maka ini akan membahayakan pada daerah dibawahnya, karena akan terjadi sedimentasi secara

Tabel 1. Distribusi Penyebaran Kota-Kota di DAS Grindulu

\begin{tabular}{lcccc}
\hline \hline \multirow{2}{*}{ Nama Kota } & Piksel & Prosentase $\mathbf{( \% )}$ & \multicolumn{2}{c}{ Luas } \\
\cline { 4 - 5 } & & & $\mathbf{( H a )}$ & $\mathbf{( K m}^{\mathbf{2}} \mathbf{1}$ \\
\hline PACITAN & 73.306 & 90,6 & $59.377,7$ & 593,8 \\
PONOROGO & 3.117 & 3,9 & $2.524,4$ & 25,2 \\
WONOGIRI & 4.488 & 5,5 & $3.635,0$ & 36,4 \\
\hline JUMLAH & $\mathbf{8 0 . 9 1 0}$ & $\mathbf{1 0 0 , 0}$ & $\mathbf{6 5 . 5 3 7 , 1}$ & $\mathbf{6 5 5 , 4}$ \\
\hline
\end{tabular}

Sumber: Hasil Analisis

Keterangan : $\quad$ Piksel = ukuran bagian terkecil elemen ukuran $30 \times 30 \mathrm{~m}$ di lapangan untuk citra Landsat 


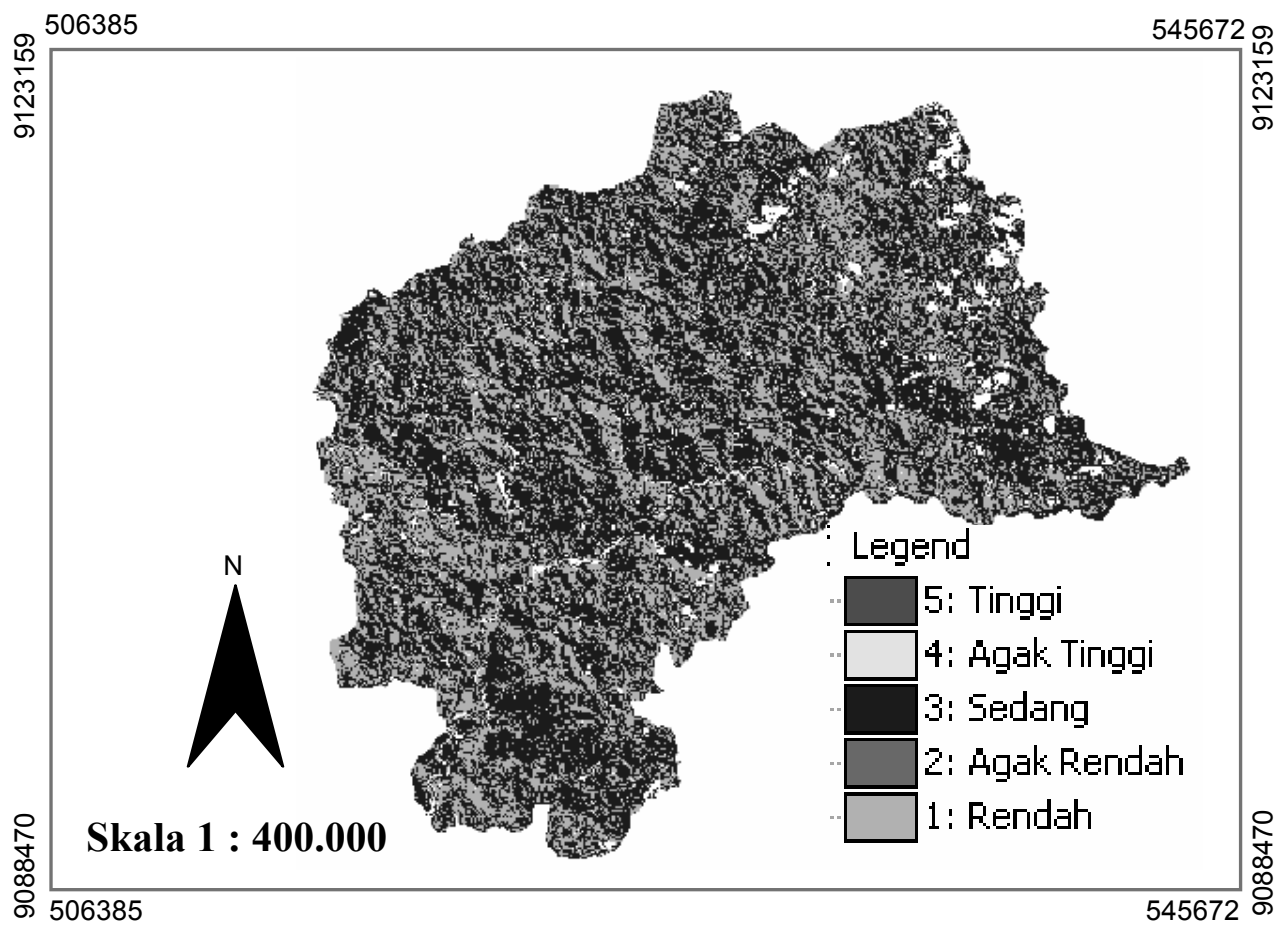

Sumber: Hasil Analisis

Gambar 3. Peta Kelas Kedalaman Tanah (Solum) DAS Grindulu, Pacitan

Tabel 2. Sebaran Luas untuk Kelas Solum Tanah di DAS Grindulu

\begin{tabular}{ccccrrr}
\hline \hline \multirow{2}{*}{ Skor } & \multicolumn{2}{c}{ Besaran Solum Tanah } & Kategori & \multicolumn{2}{c}{ Luas } \\
\cline { 2 - 3 } \cline { 6 - 6 } & Solum (cm) & Deskripsi & Nilai & Area & Prosentase (\%) \\
\hline 1 & $<15$ & Sangat Dangkal & Tinggi & 0,0 & 0,0 \\
2 & $15-30$ & Dangkal & Agak Tinggi & 0,0 & 0,0 \\
3 & $30-60$ & Sedang & Sedang & 406,5 & 62,0 \\
4 & $60-90$ & Dalam & Agak Rendah & 0,0 & 0,0 \\
5 & $>90$ & Sangat Dalam & Rendah & 248,9 & 38,0 \\
\hline & Jumlah & & $\mathbf{6 5 5 , 4}$ & $\mathbf{1 0 0 , 0}$ \\
\hline
\end{tabular}

Sumber: Hasil Analisis 
besar-besaran, dan akan mengakibatkan pendangkalan sungai dan waduk, yang berdampak semakin menurunnya umur waduk.

Kelas solum tanah dengan resiko rendah dan sedang terhadap erosi yang mengakibatkan degradasi lahan, maka ini sesuatu yang merupakan upaya untuk menjaga penutupan lahan dan jangan sampai dibiarkan dalam keadaan terbuka yang akan berakibat terjadi erosi besarbesaran, karena secara fisik faktor lahan di DAS Grindulu berpotensi terjadi erosi ringan sampai tinggi

\section{Curah Hujan Tahunan}

Kategori kelas hujan tahunan di DAS Grindulu merata dari hulu sampai hilir sama yaitu pada kategori kelas sedang (3) yaitu berkisar antara 1001 sampai 1500 $\mathrm{mm} / \mathrm{th}$. Sehingga hujan yang terjadi baik diatas maupun dibawah menyumbangkan ke tanaman dalam jumlah yang sama dan pada kelas sedang, yaitu tanaman tidak berlebih untuk persediaan air hujan dan juga tidak terlalu kekurangan. Kondisi tersebut menyebabkan sepanjang tahun di DAS Grindulu selalu ditumbuhi dengan hijaunya tanaman, dan berdampak pada sumber mata air yang tidak pernah habis meskipun pada waktu musim kemarau sekalipun.

Tabel 3 menunjukkan bahwa sebagian besar hujan tahunan pada kelas kategori sedang, dan hanya sedikit pada kelas kategori agak tinggi dengan hujan tahunan antara 501 sampai $1000 \mathrm{~mm} / \mathrm{th}$, yaitu seluas 20 ha. Sisanya semua masuk pada kategori kelas hujan tahunan sedang.

Kelas hujan tahunan hampir semua di DAS Grindulu dari hulu sampai hilir masuk kelas kategori sedang $( \pm 100 \%)$. Gambaran seperti itu menunjukkan bahwa air bukan suatu masalah di DAS Grindulu, sehingga sepanjang tahun hampir tidak ada bedanya penutupan lahan pada musim kemarau dengan musim penghujan.

Tabel 3. Sebaran Luas untuk Kelas Hujan Tahunan di DAS Grindulu, Pacitan

\begin{tabular}{cccccc}
\hline \hline \multirow{2}{*}{ Skor } & \multicolumn{2}{c}{ Besaran Hujan Tahunan } & Kategori & \multicolumn{2}{c}{ Luas } \\
\cline { 2 - 3 } & Hujan (mm) & Deskripsi & Nilai & Area $\mathbf{( K m}^{2} \mathbf{)}$ & Prosentase (\%) \\
\hline 1 & $<2000$ & Sangat Tinggi & Rendah & 0,0 & 0,0 \\
2 & $1501-2000$ & Agak Tinggi & Agak Rendah & 0,2 & 0,0 \\
3 & $1001-1500$ & Tinggi & Sedang & 655,2 & 100,0 \\
4 & $501-1001$ & Agak Rendah & Agak Tinggi & 0,0 & 0,0 \\
5 & $<500$ & Rendah & Tinggi & 0,0 & 0,0 \\
\hline
\end{tabular}

Sumber: Hasil Analisis 


\section{Evapotranspirasi}

Evapotranspirasi yang terjadi di DAS Grindulu pada skor kategori kelas sedang (1001-1500 $\mathrm{mm} / \mathrm{th}$ ) dan agak tinggi (1505$2000 \mathrm{~mm} / \mathrm{th}$ ) dan tersebar berselang-seling dari hulu sampai hilir (Gambar 4). Skor sedang dan agak tinggi terkait dengan resiko erosi yang akan terjadi, sehingga dengan demikian erosi di DAS Grindulu sebagian besar pada tingkat sedang dan agak tinggi untuk parameter evapotranspirasi.

Tabel 4 menunjukkan bahwa evapotranspirasi tertinggi pada skor kelas sedang seluas 35.770 ha $(54,6 \%)$ dan agak tinggi seluas
28.850 ha (44\%). Sehingga faktor evapotranspirasi actual di DAS Grindulu perlu menjadi perhatian agar dapat diturunkan pada skor kategori nilai rendah atau agak rendah, agar tidak terjadi erosi tingkat sedang sampai berat.

Evapotranspirasi yang masuk pada kelas sedang dan agak tinggi yang mendominasi di DAS Grindulu. Upaya yang dapat dilakukan untuk menekan agar evapotranspirasi menurun yaitu dengan reboisasi dan penghijauan sehingga tercipta iklim mikro sejuk dan tidak menimbulkan banyak evaporasi dari tanah dan transpirasi dari tanaman.

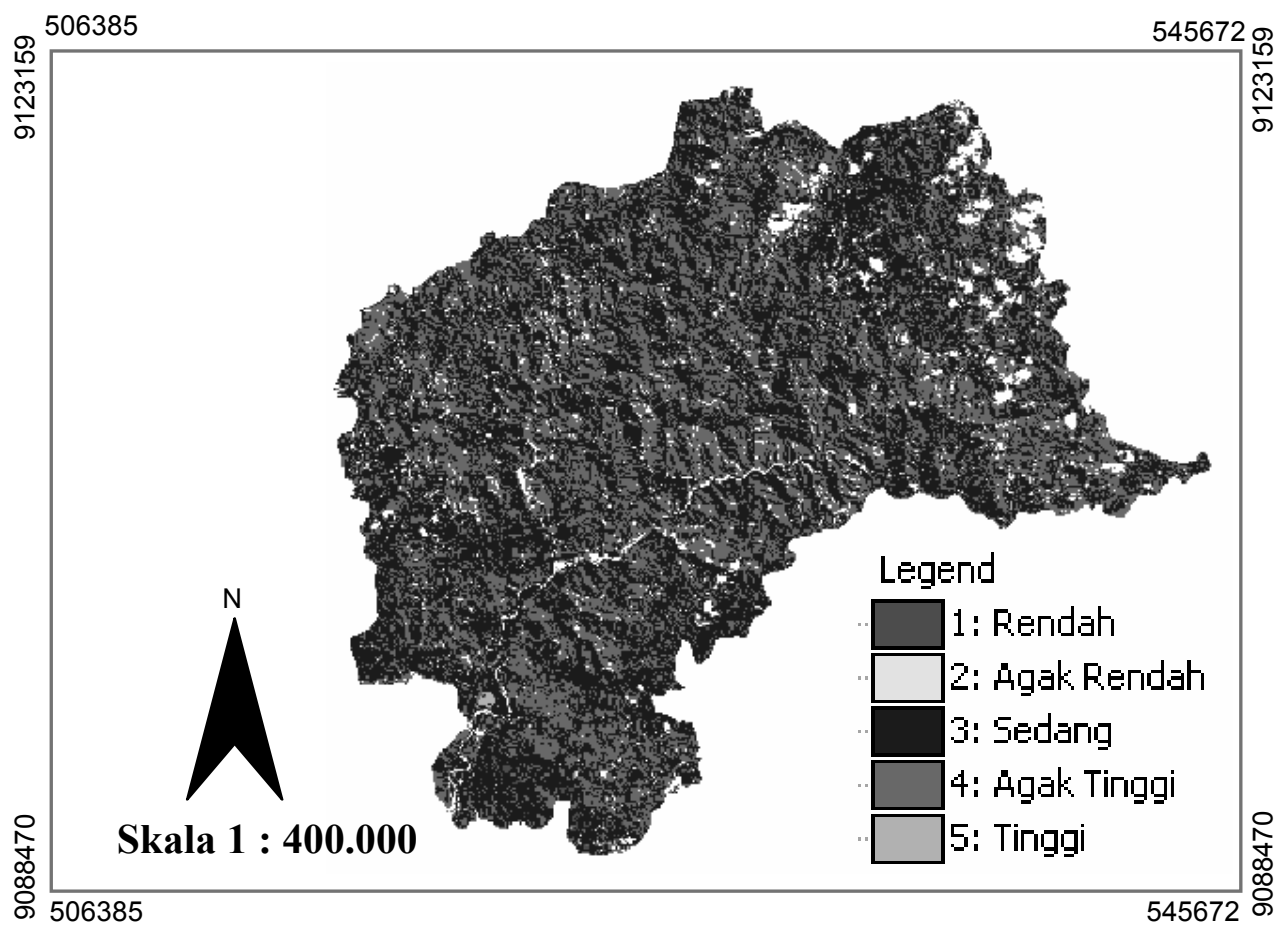

Sumber: Hasil Analisis

Gambar 4. Peta Kelas Evapotrasnpirasi Aktual DAS Grindulu, Pacitan 
Tabel 4. Sebaran Luas untuk Kelas Evapotranspirasi Aktual di DAS Grindulu

\begin{tabular}{ccccrrr}
\hline \hline \multirow{2}{*}{ Skor } & \multicolumn{2}{c}{ Besaran Evapotranspirasi Aktual } & Kategori & \multicolumn{2}{c}{ Luas } \\
\cline { 2 - 3 } & Tahunan (mm) & Deskripsi & Nilai & Area $\left.\mathbf{( K m}^{2}\right)$ & Prosentase (\%) \\
\hline 1 & $<750$ & Sangat Rendah & Rendah & 6,5 & 1,0 \\
2 & $751-1000$ & Rendah & Agak Rendah & 0,0 & 0,0 \\
3 & $1001-1500$ & Sedang & Sedang & 357,7 & 54,6 \\
4 & $1501-2000$ & Tinggi & Agak Tinggi & 288,5 & 44,0 \\
5 & $>2000$ & Sangat Tinggi & Tinggi & 2,8 & 0,4 \\
\hline
\end{tabular}

Sumber: Hasil Analisis

\section{B. Evaluasi DAS Grindulu}

\section{SES (Soil Erosion Status)}

Perhitungan erosi kualitatif SES (Soil Erosion Status) dengan 5 faktor yang berpengaruh yaitu : arah lereng, kemiringan lereng, drainase, tekstur tanah, dan penutupan lahan (Gambar 5). Skor kelas criteria untuk SES dari rendah (1) sampai tinggi (5). Erosi rendah untuk kondisi lahan yang mengalami erosi kurang dari 5 ton/ha/th.

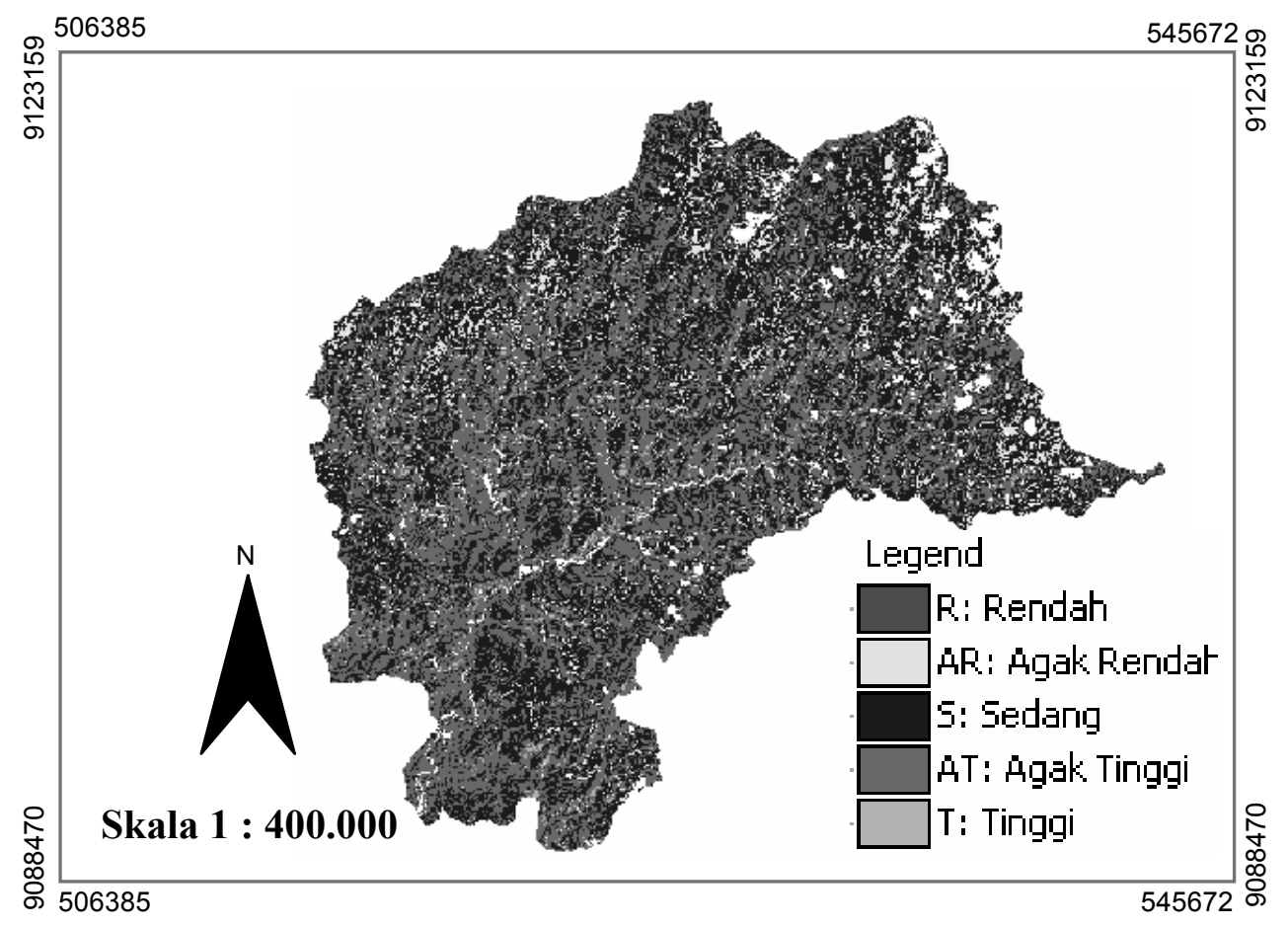

Sumber: Hasil Analisis

Gambar 5. Peta Kelas Erosi Kualitatif SES di DAS Grindulu, Pacitan 
Dari perhitungan erosi kualitatif diperoleh skor kelas erosi tertinggi pada kelas agak tinggi $(46,6 \%)$ seluas 30.250 ha dan terendah untuk kelas tinggi $(2,3 \%)$ seluas 150 ha (Tabel 5). Kondisi erosi kualitatif yang mayoritas pada tingkat sedang dan agak tinggi menyebabkan lahan di DAS Grindulu relatif mudah tererosi pada tingkat sedang dan agak tinggi, seperti terjadinya erosi alur, jurang dan longsor.
Gambar 6 grafik besarnya erosi kualitatif memperjelas gambaran bahwa erosi di DAS Grindulu sebagian besar pada tingkat sedang dan agak tinggi. Keadaan seperti tersebut sesuai dengan kondisi lahan disana yang memiliki kemiringan lereng yang curam dan tanahnya berpotensi longsor karena didominasi tekstur halus.

Tabel 5. Sebaran Luas untuk Kelas Erosi Kualitatif SES di DAS Grindulu

\begin{tabular}{|c|c|c|c|c|c|}
\hline \multirow[b]{2}{*}{ Skor } & \multicolumn{2}{|c|}{ Besaran Erosi Kualitatif } & \multirow{2}{*}{$\begin{array}{c}\text { Kategori } \\
\text { Nilai }\end{array}$} & \multicolumn{2}{|c|}{ Luas } \\
\hline & SES (t/ha/th) & Deskripsi & & Area $\left(\mathrm{Km}^{2}\right)$ & Prosentase (\%) \\
\hline 1 & $<5$ & Sangat Rendah & Rendah & 0,0 & 0,0 \\
\hline 2 & $5-10$ & Rendah & Agak Rendah & 34,7 & 5,3 \\
\hline 3 & $10-25$ & Sedang & Sedang & 300,5 & 45,9 \\
\hline 4 & $25-50$ & Tinggi & Agak Tinggi & 305,2 & 46,6 \\
\hline 5 & $>50$ & Sangat Tinggi & Tinggi & 15,0 & 2,3 \\
\hline & & & & 655,4 & 100,0 \\
\hline
\end{tabular}

Sumber: Hasil Analisis

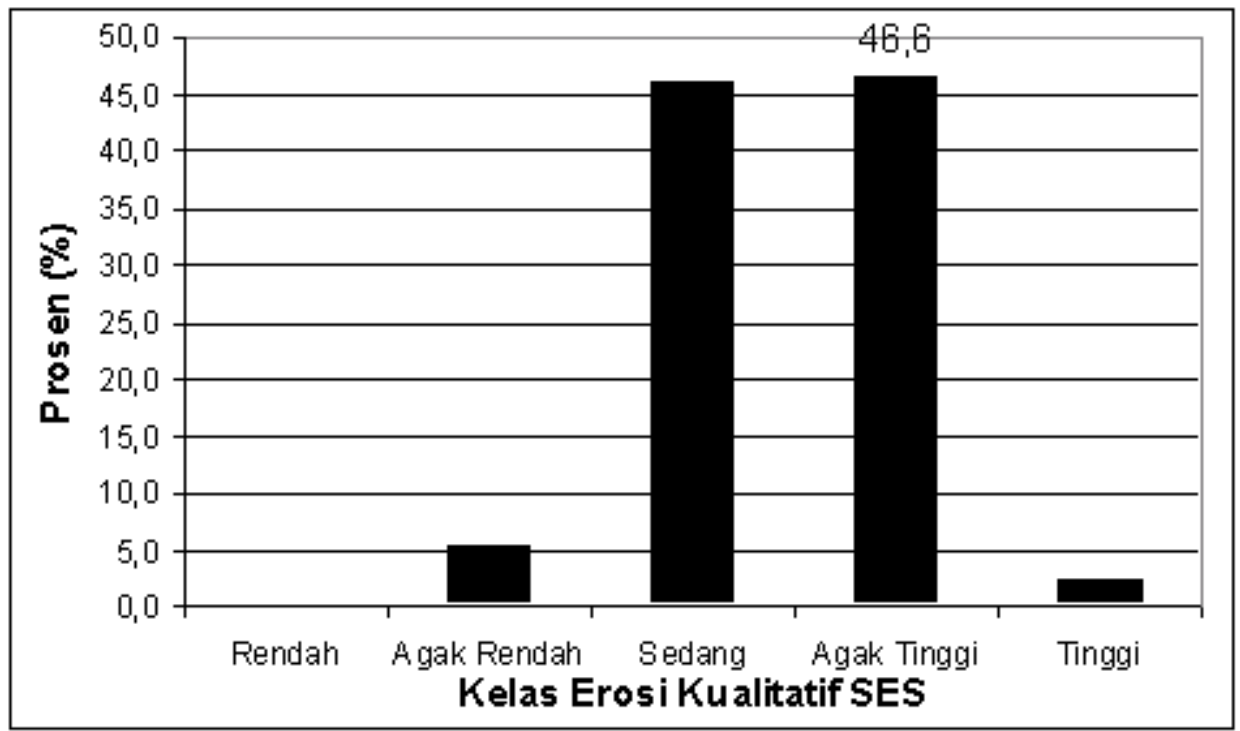

Sumber: Hasil Analisis

Gambar 6. Luasan Kategori Nilai Kelas Erosi Kualitatif SES di DAS Grindulu 


\section{MMF (Morgan Morgan dan Fenney)}

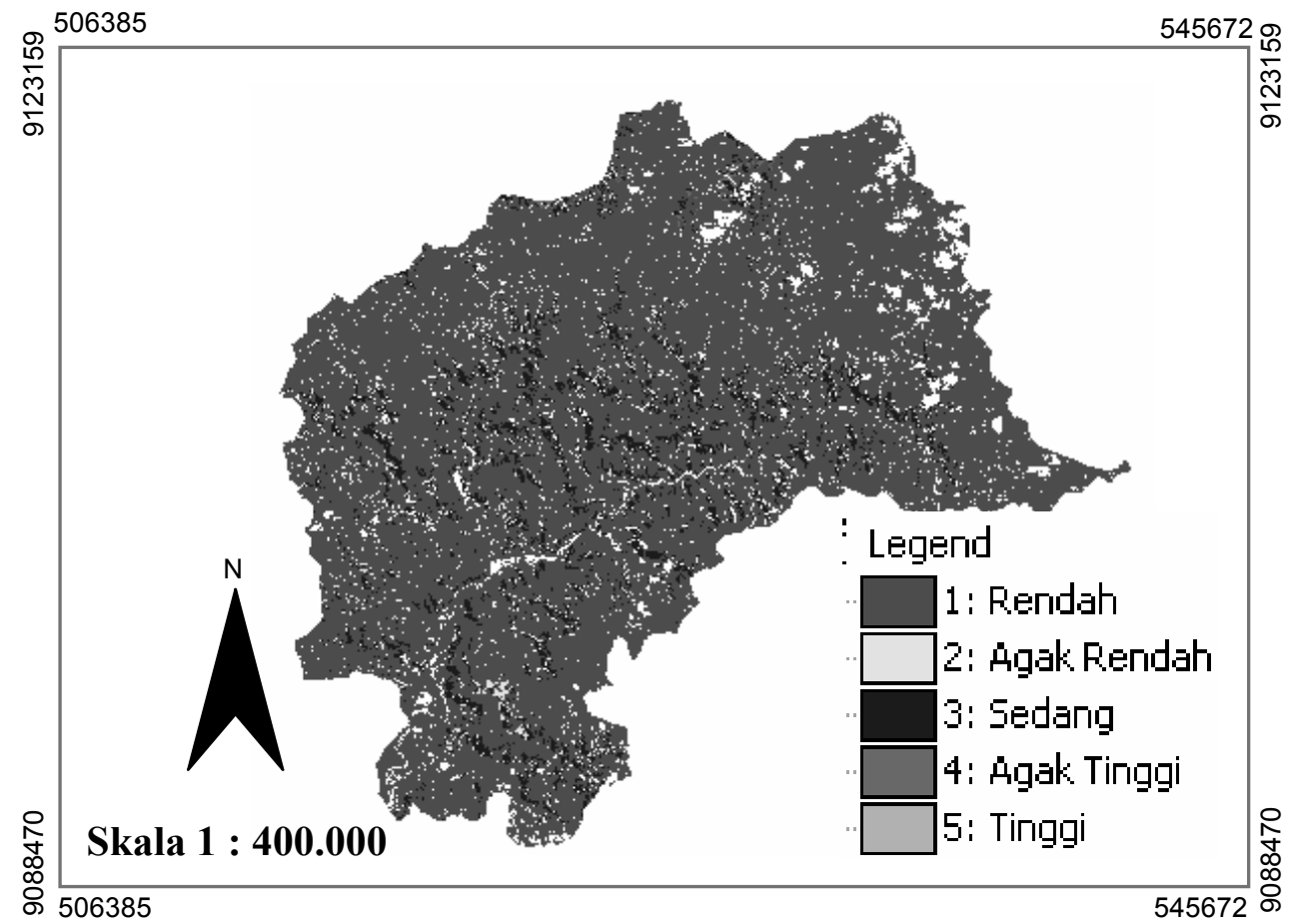

Sumber: Hasil Analisis

Gambar 7. Peta Kelas Erosi Kuantitatif MMF di DAS Grindulu, Pacitan

Erosi kuantitatif MMF (Morgan, Morgan dan Finney) dengan rumus perhitungan erosi partikel tanah dan besarnya aliran permukaan, ditetapkan dengan 5 pengkelasan dari rendah (skor 1) sampai tinggi (skor 5). Gambar 7 menunjukkan distribusi erosi kuantitatif yang didominasi warna merah atau pada tingkat erosi rendah. Hal tersebut nampaknya bertolak belakang dengan hasil perhitungan erosi kualitatif SES, tetapi karena perbedaannya untuk erosi SES lebih banyak melihat erosi secara menyeluruh sedangkan erosi MMF lebih banyak melihat besarnya erosi permukaan atau sheet erosion.

Mengingat di DAS Grindulu penutupan lahan cukup rapat maka besarnya erosi permukaan relative pada tingkat ringan sehingga dikelaskan pada kategori rendah $(90,7 \%)$ atau seluas 59.440 ha. Sehingga sebagian besar erosi yang terjadi di DAS Grindulu dari hasil perhitungan MMF dimasukkan pada skor 1 atau tingkat kategori rendah (Tabel 6). 
Tabel 6. Sebaran Luas untuk Kelas Erosi Kualitatif MMF di DAS Grindulu

\begin{tabular}{ccccrrr}
\hline \hline \multirow{2}{*}{ Skor } & \multicolumn{2}{c}{ Besaran Erosi Kuantitatif } & Kategori & \multicolumn{2}{c}{ Luas } \\
\cline { 2 - 3 } & MMF (t/ha/th) & Deskripsi & Nilai & Area $\left.\mathbf{( K m}^{2}\right)$ & Prosentase (\%) \\
\hline 1 & $<5$ & Sangat Rendah & Rendah & 594,4 & 90,7 \\
2 & $5-10$ & Rendah & Agak Rendah & 10,7 & 1,6 \\
3 & $10-25$ & Sedang & Sedang & 48,2 & 7,4 \\
4 & $25-50$ & Tinggi & Agak Tinggi & 2,0 & 0,3 \\
5 & $>50$ & Sangat Tinggi & Tinggi & 0,0 & 0,0 \\
\hline
\end{tabular}

Sumber: Hasil Analisis

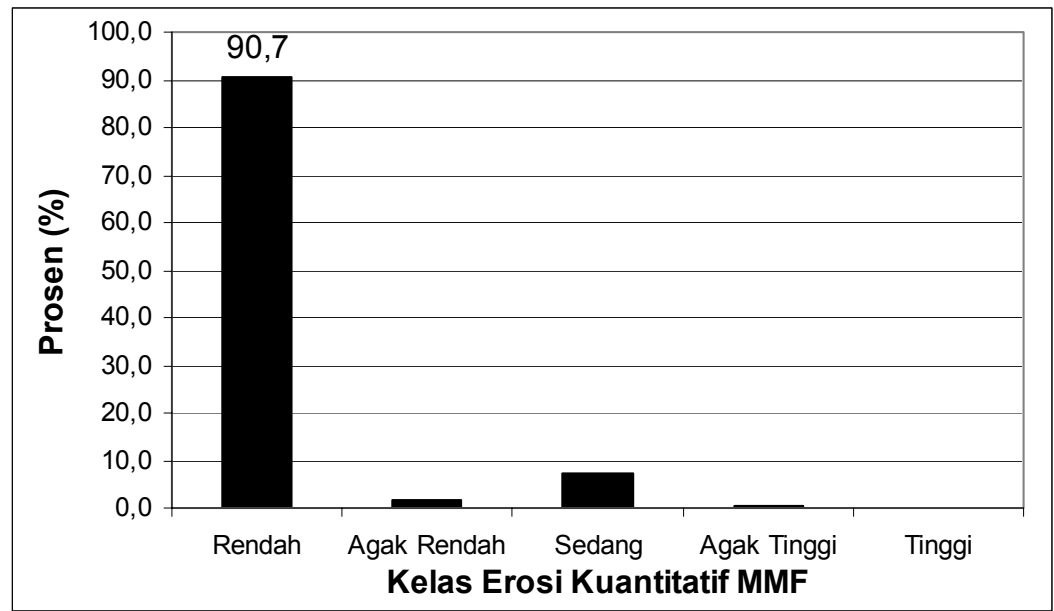

Sumber:Hasil Analisis

Gambar 8. Peta Kelas Erosi Kualitatif MMF di DAS Grindulu, Pacitan

Gambar 8 lebih memperjelas bahwa erosi permukaan dari hasil perhitungan MMF sebagian besar masuk pada kategori rendah, sebaliknya untuk perhitungan erosi SES yang melihat erosi secara menyeluruh dimasukkan pada kelas sedang sampai tinggi. Selanjutnya dari perhitungan erosi MMF untuk erosi pada tingkat kategori tinggi tidak ada. 


\section{KESIMPULAN}

Survai ISDL (Inventarisasi Sumber Daya Laban) dengan menggunakan citra satelit Landsat 7 ETM+ (Thematic Mapper) yang diambil pada bulan 11 Juli tahun 2007 dengan nomer scene Path-Row 119-066. DAS Grindulu masuk di tiga kabupaten dengan daerah dominan di kabupaten Pacitan, tercover oleh 12 peta Rupa Bumi Indonesia skala $1: 25.000$, yaitu meliputi nomer baris dan kolom 1508-121 : Kismantoro, 1508-122 : Balong, 1407-644 : Giriwoyo, 1507-433 : Bungur, 1507-434 : Arjosari, 1507-443 : Tegal Ombo, 1507-444 : Bungkal, 1407-642 : Kalak, 1507-431 : Pacitan , 1507-432 : Kebon Agung, 1507441 : Losak, 1507-442 : Sukorejo, 1507-413 : P.Bakung, 1507-414 : Wawaran, dan 1507441 : Loron.

Karakteristik dari suatu DAS (Daerah Aliran Sungai) ditentukan oleh morfometrik suatu DAS, yaitu antara lain oleh kondisi sungai, pola drainase, panjang sungai dan lain-lain. Bentuk lahan di daerah hulu didominasi Pegunungan dan Perbukitan, sedang di daerah tengah didominasi bentuk lahan Aluvial dan piedmont plan, sedang di daerah hilir kebanyakan dataran dan deposit AlluvialColluvial. Tipe batuan di daerah atas lebih banyak batuan beku yang sebagian besar sudah mulai melapuk sehingga mudah terjadi longsor, sedangkan disebelah timur selain batuan beku ada yang sedimen kapur, dan batuan metamorf. Kondisi Watershedunan konservasi tanah sampai kemiringan lebih dari 45\% masih di Watershedun teras Watershedku dan gulud dengan tingkat kualitas sedang, sehingga bidang olah sangat sempit. Jenis tanah yang dapat ditemui di DAS grindulu antara lain Entisols, Inceptisols, Ultisols dengan warna tanah didominasi warna coklat sampai kemerah-merahan, dengan kemasaman tanah antara 6 (agak masam) sampai mendekati 7 (netral).

\section{DAFTAR PUSTAKA}

Harjadi, B., 2005. Detekti Kekritisan Lahan dengan Penginderaan Jauh dan Sistem Informasi Geografis (Studi Kasus Lahan Kritis di Sub DAS Alang, Wonogiri). Forum Geografi, Vol.19 (1) Juli 2005: 1-15.

Harjadi, B., 2007. Aplikasi Penginderaan Jauh dan SIG untuk Penetapan Tingkat Kemampuan Penggunaan Lahan (KPL) (Studi Kasus di DAS Nawagaon-Maskara, Saharanpur-India). Forum Geografi, Vol. 21 (1) Juli 2007: 69-77.

Morgan, R.P.C., D.D.V. Morgan dan H.J. Finney, 1984. A Predictive Model for The Assessment of Soil Erosion Risk.J.Agric. Engng. Res., 30, 245-253.

Poveda, German dan Salazar F.Luis. 2004. Annual and Interannual (ENSO) V ariability of Spatial Scaling Properties of a Vegetation Index (NDVI) in Amazonia. Journal of Remote Sensing of Environment 93 (2004) 391 - 401.

Singh, S., 1994. Remote Sensing in The Evaluation of Morpho-hydrological Characteristics of The Drainage Basin of Jojri Catchment. J.,of Arid Zone 33(4) : 273-278. 
Shrestha, S.S., Honda K. dan Murai S., 1997. Watershed Prioritization For Soil Conversation Planning With Mos-I Messr Data. GIS Application and Socio-economic Information A Case Study of Tinau Watershed, Nepal. Space Technology Application and Research Program Asian Institute of Technology.

Uboldi J.A.dan E. Chuvieco, 1997. Using Remote Sensing and GIS to Asses Curent Land Management in the Valley of Colorado River, Argentina, ITC Journal 1997:2. 